\title{
The Government's progress in promoting choice in end-of-life care
}

\author{
Emeritus Professor Alan Glasper, University of Southampton, discusses the effectiveness of measures to deliver \\ personalisation and choice in care for people nearing the end of life
}

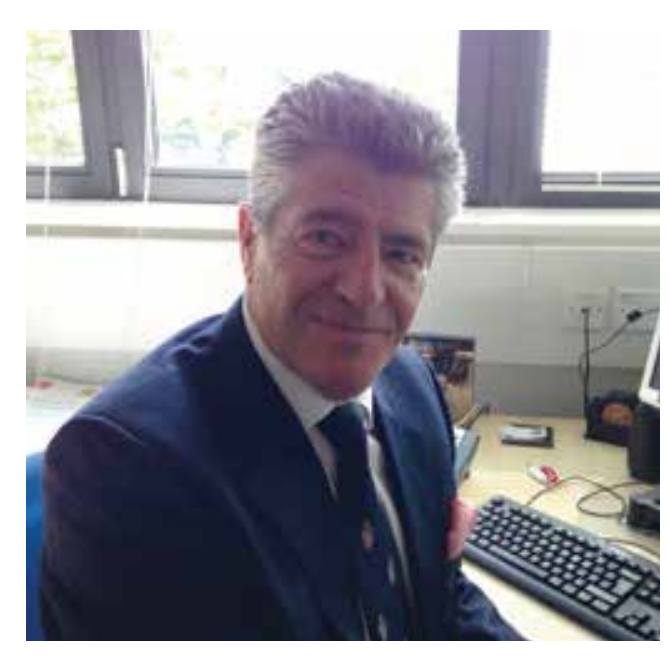

$\mathrm{T}$ he One Year On report, published in September 2017 (Department of Health (DH), 2017) is designed to show progress in ensuring that every person who is approaching life's closure has equity of access to the support they and their families need and deserve. This report follows the Government's response to an independent review of choice in end-of-life care, which had been commissioned by the $\mathrm{DH}$ and was published in February 2015 (Choice in End of Life Care Programme Board, 2015). The Government's response to this review was published in July 2016. Entitled Our Commitment to You for End of Life Care, this report attempted to provide answers to the points raised in the independent review and made a number of pledges to alleviate concerns that had been made about end-of-life care (DH, 2016). These pledges attempted to support people approaching the end of their lives to:

- Have honest discussions with health and social care professionals about their needs and preferences

- Make informed choices about their care

- Develop and document a personalised care plan

- Discuss their personalised care plans with health and social care professionals

- Involve their family, carers and those important to them in all aspects of their care as much as they want

- Know who to contact for help and advice. In its response the Government gave a clear commitment to everyone approaching the end of life that they would receive optimum care that reflected their individual needs, choices and preferences. The Government has shown its commitment to improve end-of-life care standards and it has published an interim report to show the progress that has been made in ensuring that these commitments are much more than government rhetoric.

\section{Background}

It is important to stress that the challenge of delivering consistently good experiences and outcomes for people at the end of their lives is growing. Each year, around 480000 people die in England. This is predicted to increase to 550000 by 2035 .

Additionally, the number of people with one long-term condition, many of whom will need end-of-life care, is due to rise by an additional 3 million by 2025; the number with two or three long-term conditions is projected to rise by 1.5 million. End-of-life care services will need to be responsive to these pressures and adequately resourced to reflect the extra demand over the next few years. The report suggests that about 5000 people in England alone will need to be cared for and die in care environments that will be different from those patients currently experience.

Clearly, excellence in palliative care delivery and end-of-life care is both ethically and morally a societal commitment that reflects our cultural, religious and historical background as citizens of a just and non-discriminatory country. It is perhaps the way in which we show compassion for the dying that reflects these traits. Despite this some people at life's closure are denied elements of optimum care and this is unacceptable in a society that prides itself on providing the highest standards of care from the cradle to the grave.
It was because there have been failings in care delivery for people at the end of life that the Government asked Claire Henry, the Chief Executive of the National Council for Palliative Care, to chair the independent review of choice in end-of-life care (Choice in End of Life Care Programme Board, 2015)

\section{The demise of the Liverpool Care Pathway}

Prior to this review the only toolkit of standards available for the care of the dying was the Liverpool Care Pathway (LCP). This pathway had laudable beginnings and aspirations and was developed just before the millennium by The Royal Liverpool University Hospital in partnership with the Marie Curie Palliative Care Institute. The LCP had a primary aim of providing, at all times, high-quality and dignified care for patients approaching life's end, irrespective of where the patient was being cared for, including the home or a hospice (Compassion in Dying, 2014). There were many who advocated the LCP and, in a study of its use in clinical practice, Veerbeek et al (2008) found that the pathway contributed to the quality of documentation and symptom control in the care of dying patients. There is no doubt that the use of the LCP provided a framework for non-palliative care specialist clinicians including nurses to deliver highquality end-of-life care in many different clinical domains. Despite this, Knights et al (2013) showed that the LCP had come under too much intense media scrutiny, with some popular newspapers describing it as 'a pathway to euthanasia' which compromised patient autonomy, and was used to free up beds. Although there were many supporters of the LCP who continued use it in clinical practice, the pathway fell into disrepute and further adverse newspaper headlines demonised its use after families complained that their relatives had been put on the LCP pathway without their consent, and that death 
has been hastened in people who were not dying imminently through over-prescription of powerful analgesics.

It was because the LCP was under substantial criticism that Baroness Neuberger agreed to chair an independent review of the use of the Liverpool Care Pathway. The report was published in 2013 and recommended that the name 'Liverpool Care Pathway' should be abandoned (Neuberger et al, 2013). Baroness Neuberger believed that the benign term 'end of life care plan' should replace the title LCP and would be understood by both professionals and the lay public. The review indicated that much of the problem with the LCP lay in largely preventable problems in communication between professionals and family carers, who reported to the review committee that they felt that they had been 'railroaded' into agreeing to put the dying patient on what they perceived to be a nonreversible trajectory to death. Irrespective of terminology, the review committee believed that acute hospitals in particular needed to treat patients, their relatives and carers with more respect. The review was also critical of the Nursing and Midwifery Council (NMC), which at that time offered no specific guidance to registrants on how to provide care to the dying (Neuberger et al, 2013).

This criticism prompted the NMC (2016) to incorporate such guidance in the Code to ensure that the care of the dying was fully reflected in the five priorities of care.

\section{How successful has the Government initiative been?}

It was criticism of care by Baroness Neuberger that prompted the Government to commission the independent review, quickly followed by the publication of its own response. This One Year On report attempts to show the progress made in the quest to improve end-of-life care. Sir Bruce Keogh, the National Medical Director for NHS England, is confident that progress has been made in delivering highquality end-of-life care but he also recognises that the mission to do so is an ongoing exercise (DH, 2017). It should be stressed that the Care Quality Commission (CQC) (2016) now includes care of the dying within its

$\Xi$ hospital inspection activities.

One Year On gives details of measures that have been taken to accelerate better end-oflife care. These include:

- Personalised care for people approaching the end of life, including supporting the roll-out of digital palliative and end-oflife care records to all areas by 2020. The Electronic Palliative Care Coordination System (EPaCCS) is used to help people in their final stage of life because it is important for a patient and those closest to them to have some difficult conversations, about their choices and preferences for their care and subsequent death (https://tinyurl. com/y8j4tua3)

- Measures to improve care quality for all across different settings has been addressed through CQC inspections, which rate NHS hospital and community services for end-of-life care. NHS Improvement has launched a formal improvement collaborative for trusts that have been rated as inadequate or requiring improvement to help them improve

- Innovation in the delivery of high-quality care where over the last year NHS England and regional partners have hosted nine End of Life Care Roadshow events to showcase best practice and promote personcentred care and patient empowerment. Additionally NHS England has helped develop an end-of-life care knowledge hub where best practice in care coordination for palliative and end-of-life care services can be found (https://tinyurl.com/ycnxfdau)

- National and local leadership to prioritise and improve end-of-life care. The Government has implemented a National End of Life Care Programme Board with many representatives from across the health and social care system, including service users and the voluntary sector

- The right knowledge and skills to deliver high-quality personalised care. Health Education England, for example, is addressing the undergraduate and postgraduate curricula for nursing and medicine to help improve patient choice and quality of care

- Working together with system partners and the voluntary sector. In this context the Government is seeking to strengthen its relationship with the voluntary sector through a range of initiatives including working with the National Council for Palliative Care (NCPC) and the Dying Matters group, who led the \#KnowAboutMe social media campaign to raise public understanding and expectations about record sharing in end-of-life care during March and April 2017. https:// tinyurl.com/yaxsngqw

\section{KEY POINTS}

- A publication from the Government, One Year On, aims to show progress in ensuring that every person who is approaching life's closure has equity of access to the support they and their families need

- The challenge of delivering consistently good experiences for people at the end of their lives is growing with around 480000 people dying in England a year, predicted to rise to 550000 by 2035

- Significant progress has been made across the country in making high-quality personalised end-of-life care a reality for all who require it

- Strengthening accountability and transparency to drive improvements: as part of its overall quest, NHS England has developed metrics to assess quality and experience in end-of-life care.

\section{Conclusion}

The One Year On report shows that significant progress has been made across the country in making high-quality personalised end-of-life care a reality for all who require it. How endof-life care is tailored to an individual's needs and preferences remains pivotal to the practice of nurses working in this domain. BJN

Care Quality Commission. 'A different ending': Our review looking at end of life care published. 9 May 2016. https:// tinyurl.com/yafe6j6y (accessed 1 December 2017)

Choice in End of Life Care Programme Board. What's important to me: a review of choice in end of life care. 2015. https://tinyurl.com/h69cdus (accessed 29 November 2017)

Department of Health. Our commitment to you for end of life care: the government response to the review of choice in end of life care. 2016. https://tinyurl.com/ y7ucaywb (accessed 29 November 2017)

Department of Health. One year on: the government response to the review of choice in end of life care. 2017. https://tinyurl.com/y7fxx2on (accessed 29 November 2017)

Compassion in Dying. What happened to the Liverpool Care Pathway? Factsheet. 2014. https://tinyurl.com/yaluvo5e (accessed 30 November 2017)

Knights D, Wood D, Barclay S. The Liverpool Care Pathway for the dying: what went wrong? Br J Gen Pract. 2013; 63(615): 509-510

Neuberger J, Aaronovith D, Bonser T et al, Independent Review of the Liverpool Care Pathway. More care, less pathway: a review of the Liverpool Care Pathway. 2013. https://tinyurl.com/y7nu6lxo (accessed 30 November 2017)

Nursing and Midwifery Council. End of life care. Our position. 2016. https://tinyurl.com/ycsnkejj (accessed 1 December 2017)

Veerbeek L, van Zuylen L, Swart SJ et al. The effect of the Liverpool Care Pathway for the dying: a multi-centre study. Palliat Med. 2008; 22(2): 145-151 